\title{
Quantitatively Measuring Transportation Network Resilience under Earthquake Uncertainty and Risks
}

\author{
Manzhen Duan ${ }^{1}$, Dayong Wu ${ }^{2}$, Bo Dong ${ }^{1}$, Lin Zhang ${ }^{1}$ \\ ${ }^{1}$ Department of Civil and Architectural Engineering, North China University of Science and Technology, Tangshan, China \\ ${ }^{2}$ Department of Civil, Environmental and Construction Engineering, Texas Tech University, Lubbock, Texas, U.S.A
}

Email address:

1033838477@qq.com (Manzhen Duan),jasond.wu@ttu.edu (Dayong Wu),253257505@qq.com (Bo Dong),37770422@qq.com (Lin Zhang)

\section{To cite this article:}

Manzhen Duan, Dayong Wu, Bo Dong, Lin Zhang. Quantitatively Measuring Transportation Network Resilience under Earthquake Uncertainty and Risks. American Journal of Civil Engineering. Vol. 4, No. 4, 2016, pp. 174-184. doi: 10.11648/j.ajce.20160404.17

Received: January 28, 2016; Accepted: May 16, 2016; Published: June 15, 2016

\begin{abstract}
Transportation network faces the possibility of sudden events that disrupts its normal operation, particularly in earthquake prone areas. As the backbone of critical infrastructure lifelines, it is therefore essential that transportation network retains its resilience after disastrous earthquakes to ensure efficient evacuation of at-risk population to safe zones and timely dispatch of emergency response resources to the impacted area. However, predicting transportation network resilience and planning for emergency situations is an extremely challenging problem, particularly under earthquake uncertainty and risks. This paper aims to propose a model to quantify seismic resilience of transportation network. The focus of this model is on generalizing quantitative resilience measures of transportation network response to earthquake risks rather than specifying characteristics of the corridor selections that lead to patterns of the response of each specific road segment. In the model, traffic capacity is selected as resilience measure and three capacity reduction indices are introduced to address the uncertainty and risks from impacted roads, buildings and bridges, respectively. Finally, the proposed models were validated by the 2008 Sichuan Earthquake data.
\end{abstract}

Keywords: Earthquake, Transportation Network, Resilience, Uncertainty, Risks

\section{Introduction}

In the past few decades, disastrous earthquakes have frequently impacted human society and caused catastrophic life and economy losses around the world. For example, in 1999, the Chi-Chi great earthquake left Taiwan with 2,400 dead and more than ten thousand injured. Many towns and villages in the central Taiwan were destroyed. Industry and commercial activities were brought to a standstill because of power out or insufficient workface. A conservative estimate of total loss because of the earthquake was over US $\$ 9.2$ billion [1]. In the 2008 Sichuan earthquake, the deadliest one ever in China since the 1976 Tangshan earthquake, there were at least 69,195 people killed, 374,177 injured and 18,392 missing and presumed dead in the Chengdu-Lixian-Guangyuan area. More than 45.5 million people in 10 provinces and regions were affected. At least 15 million people were evacuated from their homes and more than 5 million were left homeless [2]. All highways into Wenchuan (the epicenter of this earthquake), were damaged by the quake, delaying the arrival of relief troops. In 2010, a magnitude 7.0 earthquake near Haiti devastated its capital, killing hundreds of thousands of people. Perhaps more tragic, however, was that thousands more would perish after the event due to the significant inability to transport much needed goods and services. This was in large part due to poor roads and debris, causing navigation through the streets to be nearly impossible [3].

Recent significant seismic events around the globe have increased the awareness and importance of the resilience built into the local and regional transportation network, especially when evacuation and recovery efforts were limited by system performance and available resources. In addition, as transportation network forms the "backbone" of other critical facilities, e.g., power and water lifelines, telecommunication lifelines, acute-care hospitals and emergency management organizations, among others. It is therefore essential that transportation network retains its resilience, namely, traffic-carrying capacity, after a disastrous earthquake to ensure efficient evacuation of at-risk population to safe zones and timely dispatch of emergency response resources to the impacted area. The past study indicated that Haiti suffered for 
months struggling to recover, while Chile was back on its feet within weeks. The key difference between these two examples is seismic resilience of their transportation networks.

However, predicting seismic resilience quantitatively is an extremely challenging problem, particularly in the lack of transparent performance measures of complex transportation infrastructure systems under post-earthquake uncertainty and risks. By moving beyond past qualitative conceptualizations, this paper aims to provide a more quantitative and operational model to predict transportation network resilience after earthquake and helps decision makers with formulating and applying risk mitigation policies and measures, especially for pre-disaster planning and preparedness. It is noteworthy that the focus of this model is on generalizing quantitative resilience measures of transportation network response to earthquake risks rather than specifying characteristics of the corridor selections that lead to patterns of the response of each specific road segment.

Transport network may experience significant functional loss due to damaged roads, collapsed buildings and destroyed bridges on the network. Furthermore, in the period of post-earthquake, stochastic damages, sudden increase of traffic flows and pedestrian streams result in uncertainty and risks, making the situation even worse. In this complex context, traffic capacity seems reasonable to be selected as a feasible measure to quantify seismic resilience of transportation network. Accordingly, three capacity indices will be applied to address the uncertainty and risks from damaged roads, collapsed buildings, and destroyed bridges along road segments, which are: the road reduction index, the building reduction index, and the bridge reduction index.

The remainder of this paper is organized as follows: Section 2 reviews the literature related to transportation network resilience, especially focusing on the concept of qualitative and quantitative resilience measures. Section 3 proposes a comprehensive model to quantitatively measure transportation network resilience, in which three reduction indices are applied to address the uncertainty and risks from the earthquake. Section 4 validates the proposed model and reduction indices by using the real data collected from the 2008 Sichuan earthquake in China. Section 5 concludes this paper with main findings and future research recommendations.

\section{Literature Review}

In general terms, resilience is a characteristic that indicates system performance under unusual conditions, recovery speed, and the amount of outside assistance required for restoration to its original functional state [4]. The concept of resilience is broadly applied throughout many different fields of study, e.g., engineering, psychology, sociology, and economics. Particularly, the resilience of transportation network can be defined as the ability for transportation network to absorb disruptive events gracefully, maintaining its demonstrated level of service, or to return itself to a level of service equal to or greater than the pre-disruption level of service within a reasonable timeframe [5]. More specially, as defined by Murray-Tuite [4], transportation resilience has ten dimensions: redundancy, diversity, efficiency, autonomous components, strength, collaboration, adaptability, mobility, safety, and the ability to recover quickly.

With the increasing awareness of protecting transportation network and its critical components against natural and man-made disasters, intensive research activities have been stimulated in the fields of structural and transportation engineering since the late 1990s [6-8]. Although most of the studies have not been extended beyond qualitative definitions on the resilience or offered little that is operational in the perspective of decision makers, some of them have made advancements in quantitative measures of resilience, including transportation and seismic resilience applications. This section will focus on reexamining quantitative resilience measures for transportation network under earthquake risks in the light of these advancements.

Bruneau et al. presented a conceptual framework to define seismic resilience of communities and quantitative resilience measures that can be useful for a coordinated research effort focusing on enhancing this resilience [6]. These measures are defined in terms of the 4R's (Robustness, Redundancy, Resourcefulness, and Rapidity) and TOSE dimensions (Technical, Organizational, Societal, and Economic). Bruneau et al. stated that the framework can be used to quantify measures of resilience for various types of physical and organizational systems. A concept definition of seismic resilience measure (or "resilience triangle") is presented in Figure 1, in which the measure, $\mathrm{Q}(\mathrm{t})$, which varies with time, has been defined for the quality of the infrastructure of a community. Specifically, performance can range from $0 \%$ to $100 \%$, where $100 \%$ means no degradation in service and $0 \%$ means no service is available. Along this line, Dorbritz [3] has made further development of resilience triangle and divided resilience into three phases: prevention, intervention and recovery. The prevention phase aims to increase the ability of systems to withstand the impacts of disastrous events on the system performance before such an event occurs. Systems should be designed in a way such they are maximally robust and the impacts on the system performance are minimized. The intervention phase tries to suggest appropriate strategies to positively influence the disaster spreading process during the impacts of them. Catastrophe management and anticipating order of failures are example for intervention measures. At each resilience phase, single or multiple quantitative measures can be used to characterize the system performance, as shown in Figure 2.

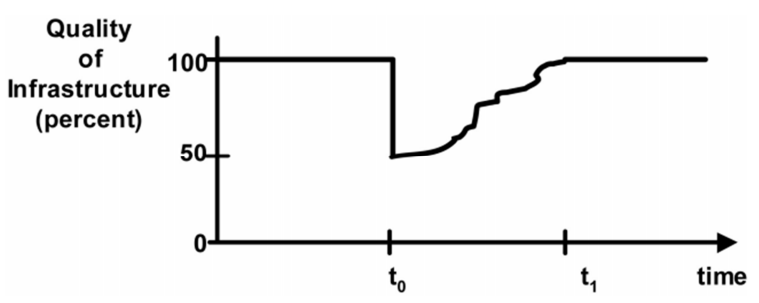

Figure 1. Conceptual Resilience Measures Proposed by Bruneau et al. 


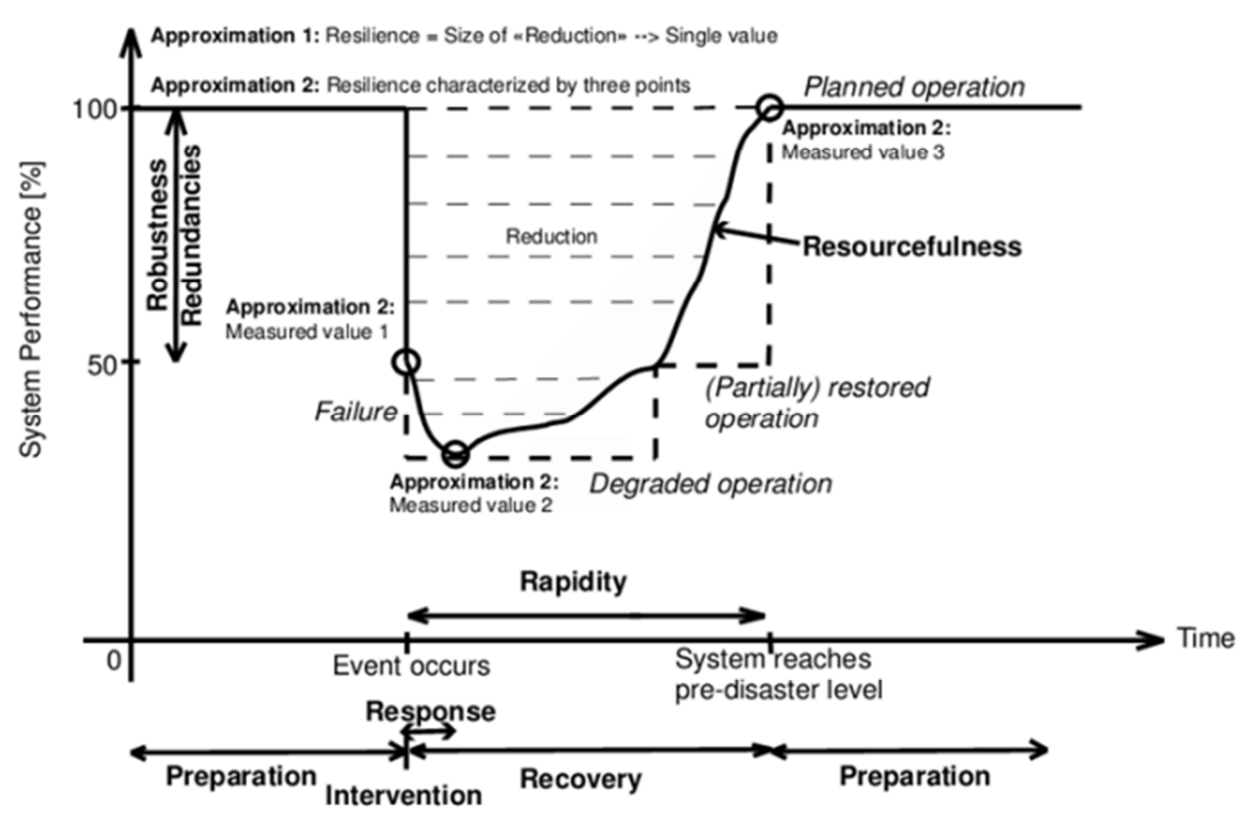

Figure 2. Detailed Resilience Measures Proposed by Dorbritz.

By following the works of Bruneau et al. [6] and Dorbritz [3], a comprehensive model is proposed in this study to measure seismic resilience of transportation network more systematically and quantitatively. In the model, the quantitative resilience measure is defined as the ratio of reduced traffic capacity of a transportation network in the post-earthquake period with respect to its original traffic capacity before the occurrence of earthquake. Traffic demands and road traffic capacities are usually random variables. More specially, these random characteristics become even more obvious during or after earthquake due to unusual increase in traffic, undirected traffic and pedestrian flows, uncertainty from road damages, building or bridge collapses, and the uncertain process of rescues due to post-earthquake blockage, among others. In this regard, the authors propose three traffic capacity reduction indices to address these risks and uncertainty, which are: the road reduction index, the building reduction index and the bridge reduction index. The road reduction index estimates the reduction of road capacity under the impact of earthquake. The building reduction index considers the seismic vulnerability of building structures and potential building collapses that might occupy the road area after a major earthquake occurs. The bridge reduction index addresses the susceptibility of bridges to natural and man-made hazards and the impact of their closure to the whole transportation network. Specially, more attention will be paid to the long-span and high-pier bridges, since they are more vulnerable to earthquake than other types of infrastructures.

Recently, considerable studies have been conducted to develop traffic capacity models for transportation network under earthquake disasters. For example, Song [9], Du [10], and $\mathrm{Li}$ [11] established the prediction models of post-earthquake blockage due to collapsed building debris. Liu [12] analyzed the vulnerability of urban road system in earthquake disasters. Li [13] established a theoretical model to predict highway capacity after strong earthquakes. Wang [14] and Lan [15] studied the damage of highway bridges after earthquake. Elise M. H. proposed an exact methodology of measuring a network's maximum resilience level [16]. Alberto proposed a probabilistic approach for the pre-event assessment of seismic resilience of bridges, including uncertainties associated with expected damage, restoration process and rebuilding/rehabilitation costs [17]. A case study approach was taken to examine the transportation organizational service provision in one of the most devastated communities after the 2011 Japanese earthquake and tsunami [18]. A stochastic, time-dependent integer program with recursive functions is proposed for the problem of assessing a rail-based freight transportation system's resilience to disaster events [19]. However, some limitations have been found in these studies: 1) the previous models focused on the earthquakes within a relatively narrow range of magnitudes, especially lack of supporting for the intensity of XI or above, e.g., the 2008 Sichuan earthquake; 2) the existing models failed to consider the comprehensive effects from damaged roads, building and bridges simultaneously. More specially, there were very limited studies on the seismic effects of high-pier and large-span bridges; 3 ) the past studies cannot fully address the uncertainty and risks in a complex environment after earthquake.

Attempting to overcome these limitations, this paper makes at least three contributions. Firstly, the authors identify and quantify seismic damage factors for roads, buildings, and bridges, especially for high intensity of earthquakes (XI or above). Secondly, the researchers propose a comprehensive model to evaluate the seismic resilience of transportation network in a more quantitative and operational way. Lastly, the authors evaluate the extent to which various uncertainty and risks on the post-earthquake transportation network. The next section will discuss the proposed seismic resilience model in more details. 


\section{Model}

In order to assess the resilience of transportation network after earthquake disasters more efficiently and effectively, the authors deem quantitative resilience measures entirely required. The researchers also think these measures are also important for estimating traffic conditions after earthquake and leading to the optimal decision-making on seismic mitigation program during the recovery period. These measures should be also simple enough to apply in practice and also address the uncertainty and risks in the complex post-earthquake environment. However, traditional performance measures used in the transportation field are either conceptually, or typically focused on individual locations by evaluating traffic congestion, or not practical enough due to very limited data in the post-earthquake period, e.g., traffic flow data on the network. To address the above issues, a post-disaster resilience measure, namely, traffic capacity, is selected for evaluating the overall performance of transportation network under earthquake risks. It should emphasize both individual road condition and network functionality in a more systematical and comprehensive way.

Traffic capacity reflects the supply on transportation network and should be suitable to evaluate the system resilience quantitatively in the post-earthquake period. However, traffic capacity has been affected by many uncertainty factors, such as lane width, number of lanes, vehicles composition, non-interference motor vehicles, pedestrian interruptions, driver's behavior as well as road conditions. These random characteristics become even more obvious during or after an earthquake. To address comprehensive effects of these uncertainty and risks, three capacity reduction indices are introduced in this study: the building reduction index $\left(P_{b}\right)$, the road reduction index $\left(P_{r}\right)$, and the bridge reduction index $\left(P_{q}\right)$. Then, by multiplying the basic traffic capacity with three indices, the reduced traffic capacity after earthquake disasters can be determined by Equation 1:

$$
C_{e}=C \times \sum_{i=1}^{N}\left(P_{i b} \times P_{i r} \times P_{i q}\right)
$$

Where:

$C_{e}=$ Reduced traffic capacity of the studied transportation network in the post-earthquake period;

$C=$ Basic road traffic capacity of the studied transportation network, which is the maximum traffic capacity in the free-follow condition (passenger car equivalent hour or $\mathrm{pce} / \mathrm{h})$;

$N=$ The total number of road segments on the studied transportation network;

$P_{i b}=$ The building reduction index due to the rubble of collapsed buildings along the $i^{\text {th }}$ road segment after an earthquake;

$P_{i r}=$ The road reduction index due to the damaged condition of the $i^{\text {th }}$ road segment after an earthquake;

$P_{i q}=$ The bridge reduction index due to the damage or closure of bridges of the $i^{\text {th }}$ road segment after an earthquake (take the value of 1 if there is no bridge on the $i^{\text {th }}$ road segment).

In order to understand the model in-depth, the definitions and calculation procedures of three reduction indices will be discussed in more details as follows:

\subsection{The Road Reduction Index}

The road system will be impacted greatly if a disastrous earthquake occurs resulting in the significant reduction of its traffic capacity. Attempting to capture this impact, the road reduction index $P_{r}$ has been introduced herein. Apparently, the reduced capacity of a road network is closely related to the damage condition of roads after an earthquake. Once the damage condition is quantified, the reduced road capacity can be determined correspondingly. According to the previous findings [20], the impact of an earthquake to the road system is mainly the structural damage of pavements and their embankments, which can be quantified by the average quake damage index $k_{i}$, as shown in Equation 2 [21]:

$$
k_{i}=0.2 \times\left(\prod_{j=1}^{7} X_{i j}\right)-0.1
$$

Where:

$k_{i}=$ the average quake damage index for the $i^{\text {th }}$ road segment;

$X_{i j}=$ quantifies the impact of the $j^{\text {th }}$ quake damage factor on the $i^{\text {th }}$ road segment.

The values of $X_{i j}$ are summarized in Table 1 for seven major quake damage factors [22]. It should be noted that this study mainly focus on the impact of high-intensity earthquakes, namely, the magnitudes of VII or above. More specially, the value of seismic intensity damage factor is estimated for intensity XI, which has not been found in the exiting studies.

\begin{tabular}{|c|c|c|c|c|c|}
\hline Quake Damage Factors & Quantified Values & Impact of Quake Da & ge Factor $X_{j}$ & & \\
\hline Seismic Intensity & VII (1.00) & VIII (1.05) & IX $(1.15)$ & $X(1.20)$ & XI (1.30) \\
\hline Embankment Soil Category & Hard soil $(0.90)$ & Clay (1.00) & Fine sandy silt (1.10) & Stage construction (1.20) & \\
\hline Site Soil Category & Class I (0.90) & Class II (1.00) & Class III (1.10) & Class IV (1.30) & \\
\hline Extent of Foundation Damage & No $(1.00)$ & Slight (1.05) & Moderate (1.15) & Serious $(1.40)$ & \\
\hline Embankment Type & $\begin{array}{l}\text { Low Embankment } \\
(1.00)\end{array}$ & $\begin{array}{l}\text { Cutting Embankment } \\
(1.10)\end{array}$ & $\begin{array}{l}\text { Cutting and Filling } \\
\text { Embankment (1.30) }\end{array}$ & $\begin{array}{l}\text { Riverside Embankment } \\
\text { (1.35) }\end{array}$ & \\
\hline Embankment Height: H(m) & $\mathrm{H} \leq 1(1.00)$ & $1<\mathrm{H} \leq 2(1.05)$ & $2<\mathrm{H} \leq 3(1.10)$ & $3<\mathrm{H}(1.40)$ & \\
\hline Seismic Fortification & Fortified $(0.90)$ & Not Fortified (1.00) & Damaged (1.20) & N/A & \\
\hline
\end{tabular}

Table 1. Seven Quake Damage Factors to Roads.

Note: the values in brackets are the quantified values of $\mathrm{X}_{\mathrm{j}}$. 
It should also be noted that the impact of landslide must be taken into the consideration if there is any potential landslide risk on the $i^{\text {th }}$ road segment. In this regard, the value of $k_{i}$ will plus $0.1,0.3$, and 0.5 , if the potential landslide hazard on road segment is slight, moderate, and severe, respectively. But if the adjusted value of $k_{i}$ is greater than $1, k_{i}$ has to be taken the value of 1 , since there is no reason that the post-earthquake capacity will be greater than the original capacity.

The post-earthquake road condition has an exponential relationship with the average quake damage index $k_{i}$, which can be described by the index $P_{\text {road }}[23]$ :

$$
P_{\text {road }}=e^{-\frac{\left(k_{i}-k_{0}\right)^{2}}{\sigma^{2}}}
$$

$k_{o}=$ the minimum quake damage index of road segments on the entire road network (usually the value is taken of 0.10 );

$\sigma=$ the quake damage dispersion coefficient. The recommended values of $\sigma$ are listed in Table 2 for the high-intensity earthquakes.

Table 2. Recommended values of the quake damage dispersion coefficients.

\begin{tabular}{lllllll}
\hline $\begin{array}{l}\text { Seismic } \\
\text { Intensity }\end{array}$ & VI & VII & VIII & IX & X & XI \\
\hline$\sigma$ & 0.40 & 0.30 & 0.25 & 0.20 & 0.15 & 0.10 \\
\hline
\end{tabular}

Once the quake damage factors are determined, the road condition index $P_{\text {road }}$ can be calculated by Equations 2 and 3, and then the road reduction index $P_{r}$ will be quantified correspondingly, as shown in Table 3.

Where:

Table 3. The Road Reduction Index $P_{r}$.

\begin{tabular}{|c|c|c|c|}
\hline Road Condition & Condition Description & $p_{\text {road }}$ & $p_{r}$ \\
\hline No Damage & $\begin{array}{l}\text { No damages or only a small number of slight cracks occur in pavement and embankment. } \\
\text { No loss of load-carrying capacity. } \\
\text { Normal traffic operation without any repairs needed. }\end{array}$ & $1.0 \sim 0.95$ & \\
\hline Slight Damage & $\begin{array}{l}\text { Road surface is slightly deformed with slight degrees of crack, bulge, and subsidence. } \\
\text { Normal traffic operation with minor repairs. }\end{array}$ & $0.95 \sim 0.75$ & $p_{r}=p_{\text {road }}$ \\
\hline Moderate Damage & $\begin{array}{l}\text { Serious cracks occur in pavement and embankment with moderate degrees of bulge, subsidence, pit, sand } \\
\text { boil and shoulder instability. } \\
\text { Normal traffic operation with middle repairs. }\end{array}$ & $0.75 \sim 0.45$ & \\
\hline Serious Damage & $\begin{array}{l}\text { Pavement and embankment are severely deformed with serious degrees of sand boil, bulge, and } \\
\text { subsidence. } \\
\text { Normal traffic operation is interrupted and needs major repairs. }\end{array}$ & $0.45 \sim 0.25$ & 0 \\
\hline Destruction & $\begin{array}{l}\text { Pavement and embankment are destroyed with a wide range of severe bulge, subsidence and sand boil. } \\
\text { Normal traffic operation is totally lost. }\end{array}$ & $<0.25$ & \\
\hline
\end{tabular}

\subsection{The Bridge Reduction Index}

As the critical component of transportation network, bridge is susceptible to natural and man-made hazards and its collapse or closure may bring a significant impact to transportation network. When considering earthquake risks, although the seismic intensity is a major factor, bridge is still impacted by the combined effects of many other factors, such as design, construction, and specific site conditions, among others. In this study, the damage degree of a bridge after an earthquake can be predicted by Equation 4:

$$
A=c_{0} \prod_{j=1}^{9} \prod_{k} c_{j k}
$$

Where: $1)$;

$c_{0}=$ the adjustment coefficient (usually the value is taken of

$c_{j k}=$ the $k^{\text {th }}$ weight coefficients for the $j^{\text {th }}$ bridge quake damage factor.

The weight coefficients of bridge quake damage factors are summarized in Table 4. It is noteworthy that the coefficients for higher seismic intensities, larger span lengths and higher pier heights are added into Table 4, which have not been found in the previous studies. The newly added coefficients have been marked with italics in the table.

\begin{tabular}{|c|c|c|c|c|}
\hline $\mathbf{j}$ & Bridge Quake Damage Factor & $\mathbf{k}$ & Category & Weight coefficients $C_{j k}$ \\
\hline \multirow{5}{*}{1} & \multirow{5}{*}{ Earthquake Intensity } & 1 & VII & 1.00 \\
\hline & & 2 & VIII & 1.10 \\
\hline & & 3 & IX & 1.20 \\
\hline & & 4 & $\mathrm{X}$ & 1.30 \\
\hline & & 5 & XI & 1.40 \\
\hline \multirow{2}{*}{2} & \multirow{2}{*}{ Site Soil Classification } & 1 & I & 0.80 \\
\hline & & 2 & II & 1.00 \\
\hline
\end{tabular}

Table 4. The weight coefficients of bridge damage factors for high-intensity earthquakes. 


\begin{tabular}{|c|c|c|c|c|}
\hline j & Bridge Quake Damage Factor & $\mathbf{k}$ & Category & Weight coefficients $C_{j k}$ \\
\hline \multirow{6}{*}{3} & \multirow{6}{*}{$\begin{array}{l}\text { Extent of Foundation (Liquefaction or } \\
\text { instability) }\end{array}$} & 3 & III & 1.50 \\
\hline & & 4 & IV & 1.80 \\
\hline & & 1 & No & 1.00 \\
\hline & & 2 & Slight & 1.50 \\
\hline & & 3 & Severe & 1.80 \\
\hline & & 1 & Frame, Single Arch & 1.00 \\
\hline \multirow[t]{2}{*}{4} & \multirow[t]{2}{*}{ Superstructure } & 2 & Continuous Beam, Plate Girder, Multiple-Arch & 1.10 \\
\hline & & 3 & Simply Supported Beam, Cantilever Beam & 1.40 \\
\hline \multirow{3}{*}{5} & \multirow{3}{*}{ Support } & 1 & Anti-drop-beam Device & \\
\hline & & 2 & Energy Dissipation Bearing (Or Rubber Bearing) & 1.00 \\
\hline & & 3 & General Bearing & 1.10 \\
\hline \multirow{5}{*}{6} & \multirow{5}{*}{ Pier height } & 1 & $<5 \mathrm{~m}$ & 1.00 \\
\hline & & 2 & $5 \sim 10 \mathrm{~m}$ & 1.10 \\
\hline & & 3 & $10 \sim 30 \mathrm{~m}$ & 1.20 \\
\hline & & 4 & $30 \sim 50 \mathrm{~m}$ & 1.30 \\
\hline & & 5 & $>50 \mathrm{~m}$ & 1.40 \\
\hline \multirow{2}{*}{7} & \multirow{2}{*}{ Piers material } & 1 & Reinforced Concrete & 1.00 \\
\hline & & 2 & Brick, Stone, Concrete & 1.10 \\
\hline \multirow{2}{*}{8} & \multirow{2}{*}{ Foundation } & 1 & Extended Foundation, Caisson Foundation, Multi-pile foundation & 1.00 \\
\hline & & 2 & Bent piles, High Pile Caps, & 1.20 \\
\hline \multirow{2}{*}{9} & \multirow{2}{*}{ Bridge Span and length } & 1 & Span $\leq 3 \mathrm{~m}$, Span length $\leq 10 \mathrm{~m}$ & 1.00 \\
\hline & & 2 & Span $>3 \mathrm{~m}$, Span length $>10 \mathrm{~m}$ & 1.20 \\
\hline
\end{tabular}

Based on the bridge damage degree $(A)$, bridges can be divided into five classes and the corresponding quake damage factor $K$ can be defined as shown in Table 5.

Table 5. Quantified Values of Bridge Quake Damage Factors.

\begin{tabular}{|c|c|c|c|}
\hline $\begin{array}{l}\text { Degrees of Bridge } \\
\text { Damage }\end{array}$ & Damage Description & $\begin{array}{l}\text { Bridge Damage } \\
\text { Degree (A) }\end{array}$ & $\begin{array}{l}\text { Quake Damage } \\
\text { Factor (K) }\end{array}$ \\
\hline \multirow{3}{*}{ Collapse } & Piers are impaired, collapsed, or buckled. & \multirow{3}{*}{$4.4 \sim 5$} & \multirow{3}{*}{$>0.88$} \\
\hline & Beams are fallen off. & & \\
\hline & Bridge is totally not functional. & & \\
\hline \multirow[t]{2}{*}{ Serious Damage } & $\begin{array}{l}\text { Main load-bearing structures of bridge are severely damaged, e.g., piers slip, fracture or } \\
\text { severely tilt. The component's capacity decreases significantly. }\end{array}$ & \multirow[t]{2}{*}{$3.38 \sim 4.4$} & \multirow[t]{2}{*}{$0.676 \sim 0.88$} \\
\hline & Bridge is in the risk state and needs major repair to assume its normal operation. & & \\
\hline Moderate Damage & $\begin{array}{l}\text { Main load-bearing structure of bridge are moderately damaged, e.g., slight tilts and } \\
\text { displacements of piers, small cracks in the connection of pile and beams, damaged or } \\
\text { displaced bearings, settlements of bridge approaches, decreased load-capacity of bridge. }\end{array}$ & \multirow[t]{2}{*}{$2.2 \sim 3.38$} & \multirow[t]{2}{*}{$0.44 \sim 0.676$} \\
\hline & Bridge can be used normally only after middle repair. & & \\
\hline \multirow[t]{2}{*}{ Minor Damage } & $\begin{array}{l}\text { No damage in load-bearing structures and no loss of the load capacity of bridge. Cracks } \\
\text { only occur in an allowable range. }\end{array}$ & \multirow[t]{2}{*}{$1.23 \sim 2.2$} & \multirow[t]{2}{*}{$0.246 \sim 0.44$} \\
\hline & The bridge can be used normally after minor repair. & & \\
\hline No Damage & $\begin{array}{l}\text { Bridge is not damaged or only slightly damaged in non-loading-bearing structures. } \\
\text { The bridge can be used normally without any repair. }\end{array}$ & $<1.23$ & $0 \sim 0.246$ \\
\hline
\end{tabular}

As discussed above, if a bridge is in the intact state, there should be no impact on traffic capacity; if a bridge is in the minor damage state, only small vehicles can pass it cautiously due to the emergency evacuation requirement in the post-earthquake period. In this situation, the capacity of the bridge and road segment should be reduced; if a bridge is in the moderate damage state, vehicles are not guaranteed to pass it, but pedestrians and bicycles may be allowed to pass; finally, if a bridge is severely damaged or even collapsed, it needs to be closed for the traffic. Considering the above situations, the quantified values of bridge reduction index is provided in Table 6 .

Table 6. Bridge Reduction Index $P_{q}$.

\begin{tabular}{llllll}
\hline Damaged degree & No damage & Minor damage & Moderate damage & Severe damage & Collapse \\
\hline $\mathrm{K}$ & $0 \sim 0.246$ & $0.246 \sim 0.44$ & $0.44 \sim 0.676$ & $0.676 \sim 0.88$ & $>0.88$ \\
$P_{q}$ & 1 & $1-K$ & 0 & 0 \\
\hline
\end{tabular}

Note: If there is not any bridge on the road segment, the bridge reduction index is taken the value of 1. 


\subsection{The Building Reduction Index}

Buildings may be partially damaged or even entirely collapsed by an earthquake, depending on their distances from the epicenter of earthquake and its magnitude. The potential collapsed building rubbles may occupy a portion of road and the road basic capacity needs to be reduced by multiplying the building reduction index $P_{b}$. The calculation of $P_{b}$ is described as follows.

First, the percentage of damaged or collapsed area of a building along the road, which is denoted as $\psi_{k}$, needs to be calculated, as shown in Equation 5 [10]:

$$
\psi_{k}=0.5 Y_{k}+D_{k}
$$

Where:

$Y_{k}=$ the percentage of severely damaged building area of the $\mathrm{k}$ type of building;

$D_{k}=$ the percentage of collapsed building area of the k type of building;

$K=$ the structure type of building;

Next, the collapsed rubble area of the buildings along a road segment can be calculated by Equation 6:

$$
B=\sum_{k=1}^{i} \psi_{i k} \cdot B_{i k}
$$

Where:

$B_{i k}=$ the area of the k-type building along the $\mathrm{i}^{\text {th }}$ road segment;

$B=$ the total area of the buildings along the $\mathrm{i}^{\text {th }}$ road segment.

Then, the rubble blocking density can be calculated by Equation 7:

$$
Q=\frac{B}{l \times b}
$$

Similarly, the critical rubble blocking density that is dependent on the capacity of debris removal can be defined by
Equation 8:

$$
Q_{c}=\frac{B_{c}}{l_{c} \times b_{c}}
$$

Where:

$l=$ road length;

$l_{c}=$ critical road length;

$b=$ road width;

$b_{c}=$ critical road width.

Finally, the building reduction index accounted for the blocking effect of collapsed buildings on road traffic capacity after an earthquake disaster can be calculated by the ratio of $Q$ and $Q_{C}$, as shown in Equation 9:

$$
P_{b}=\left\{\begin{array}{cc}
1.0-\frac{Q}{Q_{C}} & Q \leq Q_{C} \\
0 & Q>Q_{C}
\end{array}\right.
$$

\section{Model Validation}

In this section, the proposed model were validated by the real data observed from one of the greatest earthquakes in China's history: the 2008 Sichuan earthquake, also known as the Wenchuan earthquake. It was measured at the magnitude of 8.0 according to the Chinese official sources. Three capacity reduction indices were examined individually and the results have presented the good consistency with the real damage conditions.

\subsection{Validation of the Road Reduction Index}

The data in Table 7 are collected from the previous studies of Sichuan earthquake [24-26] and aims to validate the accuracy of the proposed road reduction index. Based on the

\begin{tabular}{|c|c|c|c|c|}
\hline \multicolumn{2}{|c|}{ Road Segment } & \multirow{2}{*}{$\begin{array}{l}\text { Dengsheng -Wolong Segment of } \\
\text { Yingri road (Figure 3) } \\
10(1.20)\end{array}$} & \multirow{2}{*}{$\begin{array}{l}\text { Hanwang Road Segment of Mianzhu } \\
\text { City (Figure 4) } \\
10(1.20)\end{array}$} & \multirow{2}{*}{$\begin{array}{l}\text { Bailu Road Segment } \\
\text { (Figure 5) }\end{array}$} \\
\hline & Seismic intensity & & & \\
\hline & Embankment soil Category & Hard soil $(0.90)$ & Fine sand (1.1) & Fine sand (1.1) \\
\hline Quake & Site soil category & Class II (1.00) & Class II (1.00) & Class II (1.00) \\
\hline Damage & Extent of Foundation Damage & Serious (1.40) & Moderate (1.15) & Serious (1.40) \\
\hline Factors & Embankment Type & Embankment along river (1.35) & Excavation and filling combined (1.30) & Low embankment (1.00) \\
\hline & Fortification & No fortification (1.00) & No fortification (1.00) & No fortification (1.00) \\
\hline \multicolumn{2}{|l|}{$X_{i j}$} & 2.2453 & 1.794 & 2.002 \\
\hline \multicolumn{2}{|l|}{$k_{i}$} & 0.84906 (Severe landslide +0.5$)$ & 0.2588 & 0.3004 \\
\hline \multicolumn{2}{|l|}{$p_{\text {road }}$} & $\approx 0$ & 0.3260 & 0.018 \\
\hline \multicolumn{2}{|c|}{$\mathrm{P}_{\mathrm{r}}$} & 0 & 0 & 0 \\
\hline \multicolumn{2}{|c|}{ Observed Damage Degree } & Destruction (Figure 3) & Severely damaged (Figure 4) & Destruction (Figure 5) \\
\hline \multicolumn{2}{|c|}{ Whether Passable after earthquake } & Impassable & Passable after being repaired & Impassable \\
\hline
\end{tabular}
proposed methodology, the results of $P_{\text {road }}$ and $P_{r}$ from the model have presented a good consistency with the real data observed in the field, as shown in Figure 3-5.

Table 7. Validation of the Road Reduction Index.

Note: The values in bracket are corresponding quantized value 


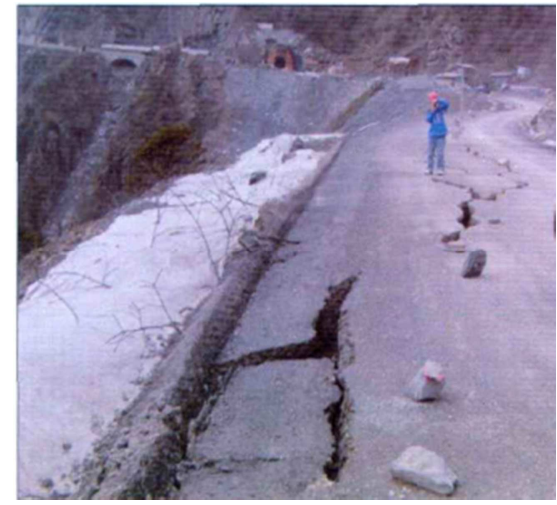

Figure 3. Yingri road: Dengsheng-Wolong Segment.

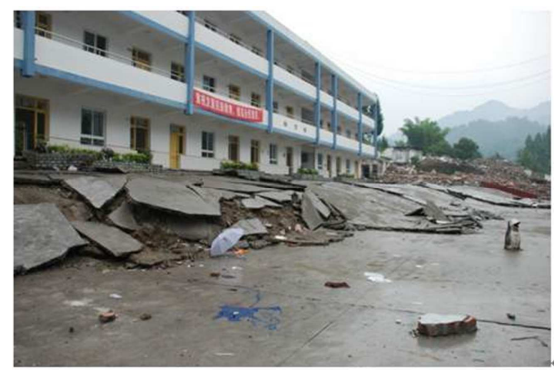

Figure 4. Bailu Middle School Road Segment.

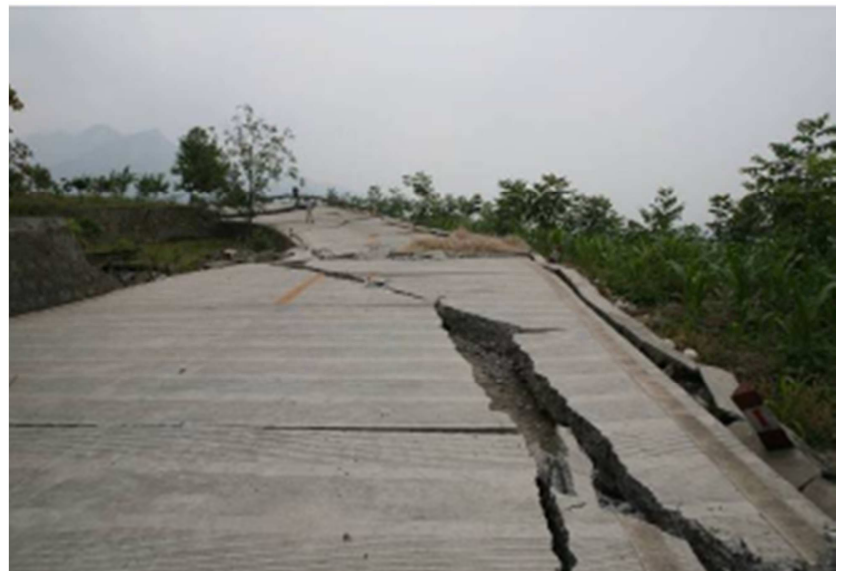

Figure 5. Hanwang Road Segment of Mianzhu City.

\subsection{Validation of the Bridge Reduction Index}

Based on the existing studies of the 2008 Sichuan earthquake, eight bridges with sufficient information have been selected to validate the proposed bridge reduction index, as shown in Tables 8 and 9 [27-29]. The results of $P_{q}$ have shown the predicted traffic capacities of eight bridges have matched well with the observed damages after the earthquake.

Table 8. Seismic Damage Information of Eight Bridges.

\begin{tabular}{|c|c|c|c|c|c|}
\hline Bridges & Baihua bridge & Fujiang bridge & Xinfangzi bridge & Miaoziba bridge & Huilan Interchange \\
\hline Seismic Intensity & XI (1.4) & $\mathrm{X}(1.3)$ & $\mathrm{XI}(1.4)$ & $\operatorname{IX}(1.2)$ & VIII (1.1) \\
\hline Site Soil Classification & Class II (1.0) & Class II (1.0) & Class II (1.0) & Class II (1.0) & Class II (1.0) \\
\hline Extent of Foundation Damage & Serious (1.8) & Light (1.5) & Light (1.5) & Light (1.5) & Light (1.5) \\
\hline Super- structure & $\begin{array}{l}\text { Continuous beam } \\
\text { (1.1) }\end{array}$ & $\begin{array}{l}\text { Simply supported } \\
\text { beam (1.4) }\end{array}$ & $\begin{array}{l}\text { Continuous beam } \\
\text { (1.1) }\end{array}$ & $\begin{array}{l}\text { Simply supported } \\
\text { beam (1.4) }\end{array}$ & $\begin{array}{l}\text { Continuous beam } \\
\text { (1.1) }\end{array}$ \\
\hline Support & rubber bearings (1.0) & rubber bearings $(1.0)$ & rubber bearings (1.0) & rubber bearings $(1.0)$ & rubber bearings (1.0) \\
\hline Pier Height & $30.87(1.3)$ & $10-30 \mathrm{~m}(1.2)$ & $10-30 \mathrm{~m}(1.2)$ & $102.47 \mathrm{~m}(1.4)$ & $2 \sim 7 \mathrm{~m}(1.0)$ \\
\hline Pier Material & $\begin{array}{l}\text { Reinforced concrete } \\
(1.0)\end{array}$ & $\begin{array}{l}\text { Reinforced concrete } \\
(1.0)\end{array}$ & $\begin{array}{l}\text { Reinforced concrete } \\
(1.0)\end{array}$ & $\begin{array}{l}\text { Reinforced concrete } \\
\text { (1.0) }\end{array}$ & $\begin{array}{l}\text { Reinforced concrete } \\
(1.0)\end{array}$ \\
\hline Foundation & $(1.2)$ & $(1.2)$ & $(1.2)$ & $(1.2)$ & $(1.2)$ \\
\hline Bridge span and length & $5 \times 20 \mathrm{~m}(1.2)$ & $10 \times 20 \mathrm{~m}(1.2)$ & $126 \mathrm{~m}(1.2)$ & $5 \times 50 \mathrm{~m}(1.2)$ & $316 \times 38 \mathrm{~m}(1.2)$ \\
\hline
\end{tabular}

Table 9. Validation of the Bridge Reduction Index.

\begin{tabular}{|c|c|c|c|c|c|}
\hline Bridges & $\begin{array}{l}\text { Baihua bridge } \\
\text { (Figure 6) }\end{array}$ & $\begin{array}{l}\text { Fujiang bridge } \\
\text { (Figure 7) }\end{array}$ & $\begin{array}{l}\text { Xinfangzi bridge } \\
\text { (Figure 8) }\end{array}$ & $\begin{array}{l}\text { Miaoziba Bridge } \\
\text { (Figure 9) }\end{array}$ & $\begin{array}{l}\text { Huilan Ramp Bridge } \\
\text { (Figure 10) }\end{array}$ \\
\hline Observed damage Degree & Destruction & Destruction & Serious damage & Destruction & Serious damage \\
\hline$A$ & 5.085 & 4.623 & 3.912 & 4.979 & 2.561 \\
\hline$K$ & 1 & 0.925 & 0.782 & 0.996 & 0.512 \\
\hline The corresponding range of $K$ & $>0.88$ & $>0.88$ & $0.676 \sim 0.88$ & $>0.88$ & $0.44 \sim 0.676$ \\
\hline The corresponding $P_{q}$ & 0 & 0 & 0 & 0 & 0 \\
\hline Prediction results & Destruction & Destruction & Serious damage & Destruction & Moderate damage \\
\hline The consistency of the results & Yes & Yes & Yes & Yes & Not Match \\
\hline
\end{tabular}




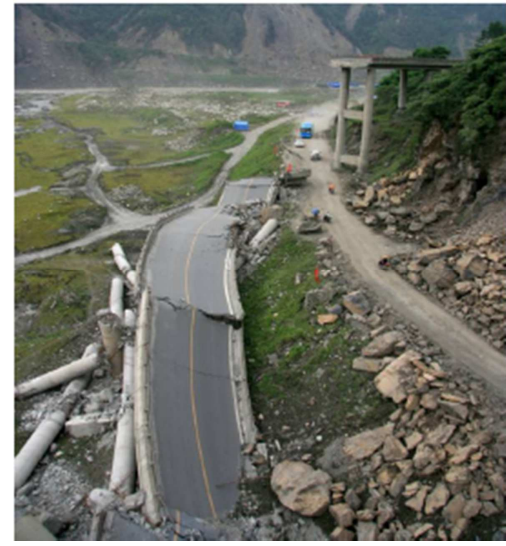

Figure 6. Baihua Bridge in National Highway G213.

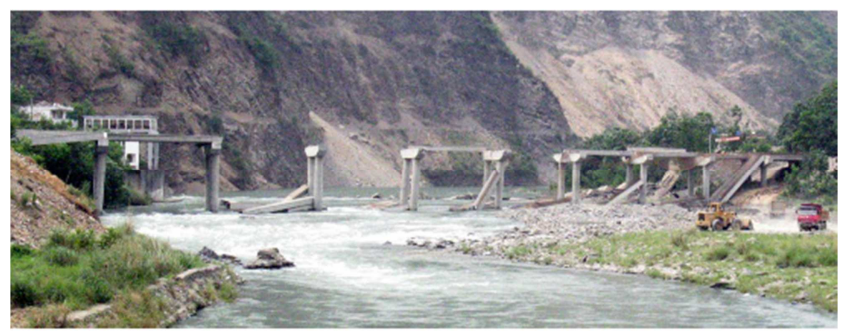

Figure 7. Fujiang Bridge in Nanba.

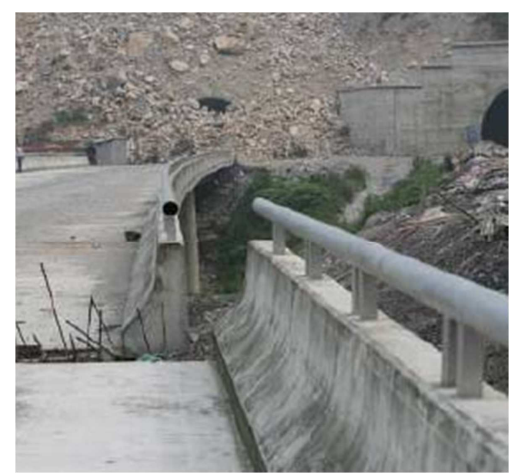

Figure 8. Xinfangzi Bridge on Dujiangyan-Wenchuan Highway.

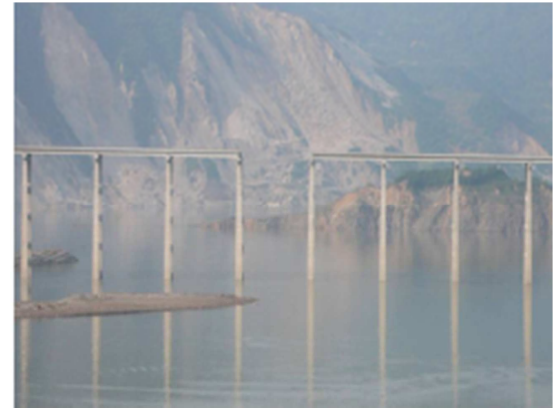

Figure 9. Maoziba Bridge in Dujiangyan-Wenchuan Highway.

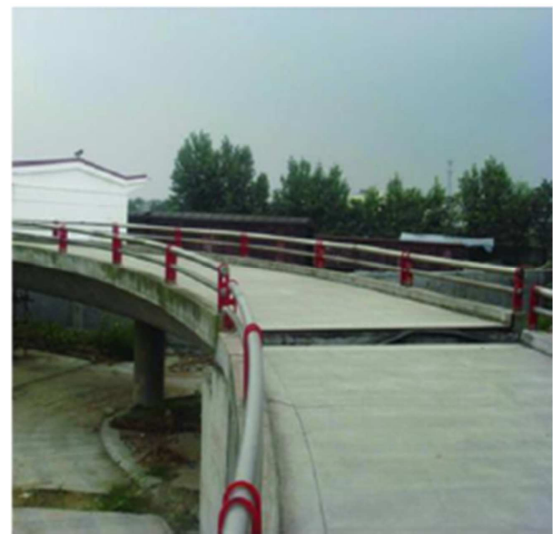

Figure 10. Huilan Interchange Ramp Bridge " $C$ ".

\subsection{Validation of the Building Reduction Index}

To validate the proposed building reduction index, four road segments were selected to investigate the blocking effects from the damaged or collapsed buildings along them. According to the historical data and the current capacity of debris-removal vehicles, the critical rubble blocking density $\left(Q_{c}\right)$ is $5,000 \mathrm{~m}^{2}$ for a road segment with the length of 400 to $1200 \mathrm{~m}$. It can be seen from Table 10 [20], the predicted blocking effects (or the results of $P_{b}$ ) have also shown a good consistency with the real data reported from the observations after the earthquake.

Table 10. Validation of the Building Reduction Factor.

\begin{tabular}{|c|c|c|c|c|}
\hline Building & $\begin{array}{l}\text { Building I in } \\
\text { Dujiangyan City } \\
\text { (Figure 11) }\end{array}$ & $\begin{array}{l}\text { House II in Dujiangyan City } \\
\text { (Figure 12) }\end{array}$ & $\begin{array}{l}\text { Building III in } \\
\text { Dujiangyan City } \\
\text { (Figure 13) }\end{array}$ & $\begin{array}{l}\text { Building IV in Yingxiu } \\
\text { City (Figure 14) }\end{array}$ \\
\hline Seismic Intensity & $\mathrm{X}$ & $\mathrm{X}$ & $\mathrm{X}$ & XI \\
\hline Building Structure Type & First floor RC frame & Masonry structure (Brick house) & First floor RC frame & First floor RC frame \\
\hline Building Height (m) (\# of Floors) & $15.6(5)$ & $15.6(5)$ & $15.6(5)$ & $19.2(6)$ \\
\hline Building Area $\left(\mathrm{m}^{2}\right)$ & 10,000 & 10,000 & 10,000 & 5,000 \\
\hline Collapsed Floors & 1 & 5 & 1 & 1 \\
\hline Extent of Damage & Severely Damaged & Collapsed & Severely Damaged & Collapsed \\
\hline Severely Damaged Building Area (\%) & N/A & N/A & N/A & N/A \\
\hline Collapsed Building Area (\%) & $25 \%$ & $100 \%$ & $20 \%$ & $16.7 \%$ \\
\hline$b(m)$ & 20 & 15 & 15 & 15 \\
\hline$l(m)$ & 1000 & 800 & 800 & 500 \\
\hline$b_{c}(m)$ & 20 & 15 & 15 & 15 \\
\hline$l_{c}(m)$ & 1000 & 800 & 800 & 500 \\
\hline$B_{c}\left(m^{2}\right)$ & 5000 & 5000 & 5000 & 5000 \\
\hline$Q_{c}$ & 0.25 & 0.42 & 0.42 & 0.67 \\
\hline$Q$ & 0.125 & 0.167 & 0.167 & 0.111 \\
\hline$P_{b}$ & 0.5 & 0.60 & 0.60 & 0.83 \\
\hline
\end{tabular}




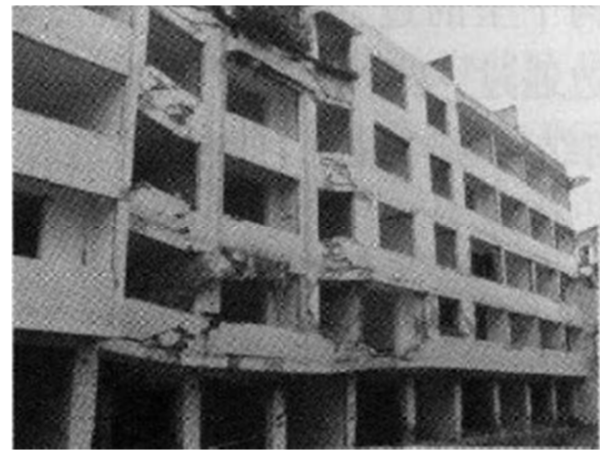

Figure 11. Masonry Building with first floor RC frame in Lotus Pond residential area of Dujiang Dam (seriously damaged).

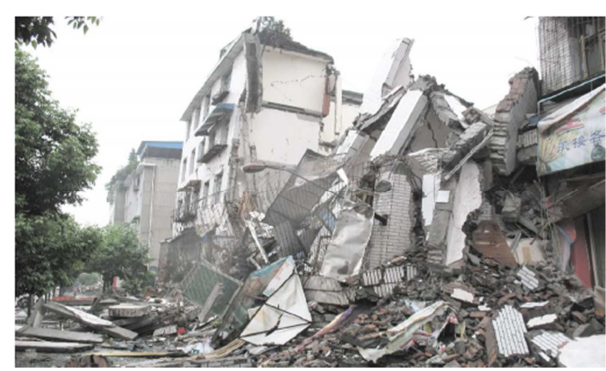

Figure 12. Masonry Building in Lotus Pond residential area of Dujiang Dam (collapsed).

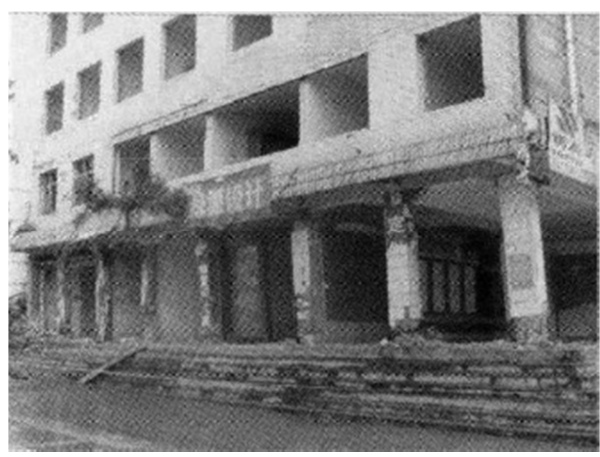

Figure 13. Masonry Building with first floor RC frame in Lotus Pond residential area of Dujiang Dam (seriously damaged).

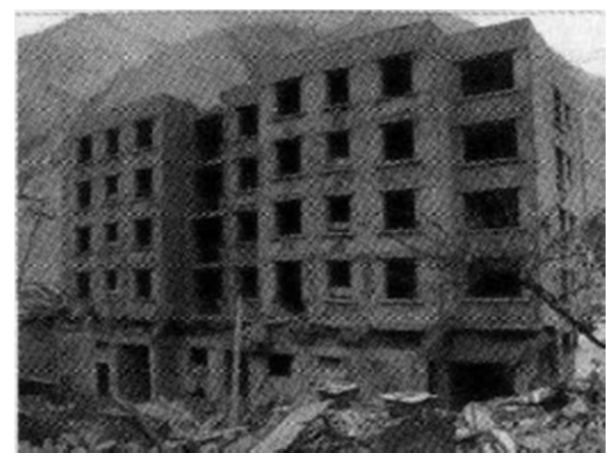

Figure 14. The 2nd floor completely collapsed in Yingxiu town (6 Floors).

\section{Conclusion}

Resiliency, if properly understood and applied, has the ability to preclude many of the devastating effects resulting from natural or man-made disasters. Transportation network with seismic resilience may reduce the probability of failure within the system as well as reduce the consequences of any failure that may occur, thus improving the time for recovery during or after disastrous earthquakes. Past resilience studies are either conceptual or not comprehensively evaluate the performance of transportation network as a whole, however, a quantitative performance measuring model should be a very useful tool for seismic hazard mitigation for transportation system. By quantifying the overall performance of transportation network, it allows the proper prioritization of investments and improvement projects. This will not merely maintaining regional transportation service in the post-earthquake period, but facilitate mitigation plans before a disastrous earthquake strikes.

This paper expands on previous studies on the transportation seismic resilience by proposing a comprehensive model to quantitatively measure the overall performance of transportation network after earthquake disasters. The focus of the model is on generalizing quantitative performance measures of a transportation network resilience response to earthquake risks rather than specifying characteristics of the corridor selections that leads to patterns of the response of each specific road segment. In the model, traffic capacity is deemed as a feasible quantitative resilience measure and three capacity reduction indices are applied to address the uncertainty and risks from damaged roads, collapsed buildings and impacted bridges along road segments in the post-earthquake period. Finally, the accuracy of the proposed model has been validated by the real data collected from the 2008 Sichuan Earthquake in China. This lays a theoretical basis for the future development of a GIS-based transportation seismic resilience system.

\section{Acknowledgments}

This research has been jointly supported by National Natural Science Fund Project (Grant No. 51378171 and Grant No. 61374157).

\section{References}

[1] Keh-Chyuan Tsai, Shyh-Jiann Hwang, "Seismic retrofit program for Taiwan school buildings after 1999 Chi-Chi earthquake." The Fourth Session of the National Earthquake Disaster Mitigation Engineering Symposium, 2009, pp. 693-703.

[2] Pan G., Tang D. L., "Damage information derived from multi-sensor data of the Wenchuan Earthquake of May 2008." International Journal of Remote Sensing, vol. 31, 2010, pp. 3509-3519.

[3] Duramy, B. F. "Women in the aftermath of the 2010 Haitian Earthquake.” 25 Emory Int'l L., 2011, pp. 1193-1215.

[4] Murray-Tuite PMA, "Comparison of transportation network resilience under simulated system optimum and user equilibrium conditions." The 2006 Winter Simulation Conference, Monterey, 2006, pp. 1398-1405. 
[5] Freckleton, Heaslip, Louisell, and Collura. "Evaluation of transportation network resiliency with consideration for disaster magnitude". TRB 2012 Annual Meeting. 2012.

[6] Bruneau, M, Chang, S, Eguchi, RT, et al. "A framework to quantitatively assess and enhance the seismic resilience of communities." Earthquake Spectra., vol. 19, 2003, pp. 733-752.

[7] Rose, A. "Defining and measuring economic resilience to earthquakes." Disaster Prevention and Management, vol. 13, 2004, pp. 307-314.

[8] Robert, D. "Assessing the resilience of transportation systems in case of large-scale disastrous events." Environmental Engineering, 2011, pp. 1070-1076.

[9] Song, J. X., and Li, J. "Simulation on accessibility of post-seismic urban transportation system." Journal of Nature Disasters, vol. 5, 1996, pp. 73-78 (in Chinese).

[10] Du, P. "Improvement for the calculating method of debris piling problem in the seismic disaster forecasting of the transportation system." World Seismic Engineering, vol. 23, 2007, pp. 161-164 (in Chinese).

[11] Li Z. J., Wang, J. Y, and Dong, F. "Randomness analysis on traffic capacity of road after seismic." Transport Engineering \& Safety, 2010, pp. 131-133 (in Chinese)

[12] Liu, C. G., Du, W., and Zhai, T. "Reliability analysis of urban transportation system." Seismic Engineering and Engineering Vibration, vol. 19, 1999, pp. 95-99 (in Chinese).

[13] Li, Y. Y., Zhou, Z. H., Jiang, Z. Z., et al. "Theoretical model of actual traffic capacity of highway post-eatrhquake". Journal of Nanjing tech university (Natural Science Edition), vol. 36, 2014, pp. 102-106 (in Chinese).

[14] Wang D. S., Feng, Q. M. "Seismic disaster assessment methods for bridges." Journal of Nature Disasters, vol. 10, 2001, pp. 113-118 (in Chinese).

[15] Lan, R. Q., Feng, B., and Wang, Z. F. "Study on the fast assessment of traffic capacity of highway bridges after strong earthquakes." World Earthquake Engineering, vol. 25, 2009, pp. 82-87 (in Chinese).

[16] Elise Miller-Hooks, Xiaodong Zhang, Reza Faturechi. Measuring and maximizing resilience of freight transportation networks. Computers \& Operations Research, vol. 39, 2012, pp. $1633-1643$.

[17] Alberto Decò, Paolo Bocchini and Dan M. Frangopol. A probabilistic approach for the prediction of seismic resilience of Bridges. Earthquake Engineering Structural Dynamics. Dyn. 2013, 42: 1469-1487.
[18] Hitomi Nakanishi, John Black, Kojiro Matsuo. Disaster resilience in transportation: Japan earthquake and tsunami 2011 International Journal of Disaster Resilience in the Built Environment Vol. 5 No. 4, 2014, pp. 341-361.

[19] Xiaodong Zhang, Elise Miller-Hooks. Scheduling Short-Term Recovery Activities to Maximize Transportation Network Resilience. J. Comput. Civ. Eng., vol. 29 No. 6, 2015, pp: 04014087.1-10.

[20] Li, B. X., and Wang, Zh. "Lessons from the performance of masonry structure with ground $\mathrm{RC}$ frame during Wenchuan earthquake." Acta Scientiarum Naturaliun Universitatis Sunyatsen I, vol. 49, 2010, pp. 22-27 (in Chinese).

[21] Jiang S. Z., and Bao F. "Vulnerability analysis of road system." Highway, 2006, pp. 106-108 (in Chinese).

[22] Li J. Lifeline engineering seismic basic theory and application. Beijing, China. 2005.

[23] Li, Y. M., Wang, L. P., and Liu, L. P. "Predictive model of post-seismic debris obstruction of collapsed buildings in mountain cities." Journal of PLA University of Science and Technology (Natural Science Edition), vol. 11, 2010, pp. 439-444 (in Chinese).

[24] Mao, C., Zhang, X. H., and Yang, X. M. "Embankment, Pavement damage investigation and reconstruction technical measures of constructing YINGRI Road". Southwest Road, 2008, pp. 245-250 (in Chinese).

[25] Bai, Y. B., and Yu, P. C. "Wenchuan earthquake major disasters fault reason analysis: For example in road Demao." Engineering Seismic Damage Investigation Analysis and Research of Wenchuan Earthquake 2009 (in Chinese).

[26] Ma H. S., Li Y. W., and Xiong J. "Wenchuan earthquake west road diseases and geological disaster investigation and analysis." Earthquake Special Issue, 2008, pp. 265-272 (in Chinese).

[27] Zhao Chuang. Unseating damages in multi-span simply supported bridges under Canyon Topography. Suzhou: Suzhou University of Science and Technology, 2012.

[28] Zhou Guoliang, Cui Chengchen, Liu Bideng et al. Failure Modes of Near-fault Bridges in Wenchuan Earthquake. Technology for Earthquake Disaster Prevention, vol. 3, 2008, pp. 370-378.

[29] Xu Xi-wei, Wen Xue-ze, Ye Jian-qing et al. The Ms 8.0 Wenchuan Earthquake Surface Ruptures and its Seismogenic Structure. Seismology and Geology, vol. 30, 2008, pp. 597-629. 